\title{
Primary School Student's Spiritual and Moral Education and Digitalization of Education: The Search for Consensus
}

\author{
Irina P. Ilinskaya* \\ Belgorod state national research University, 308015, Belgorod, (Russia), 85 Pobedy street, \\ ilinskaya@bsu.edu.ru
}

\begin{abstract}
The relevance of the research is due to the transformation digitalization of education, and changes in its common functions. The process of education digitalization has negative and positive features and development trends. In particular, the education digitalization reduces the importance of cultural and humanistic orientation of education, and its potential in the field of person's spiritual and moral education at the stage of primary general education. In this regard, this article is aimed at identifying effective pedagogical conditions for the primary school children's spiritual and moral education in a digital educational environment.

The leading methodological approach in the article is the cultural approach, which is in close relationship with the axiological and environmental approaches, which make it possible to outline the circle of traditional cultural values that serve as the basis for construction of the educational environment. Comprehension and analysis of various value systems, relevant regional pedagogical experience allows us to identify pedagogical conditions that contribute to primary school student's spiritual and moral formation in the digital educational environment.

The article offers pedagogical conditions that contribute to improve the process' efficiency of primary school students' spiritual and moral formation in the education's digitalization conditions. The materials presented in the article will help the further development of the problem, the development of the specific techniques for the primary school students' spiritual and moral education technology.
\end{abstract}

Keywords: education digitalization, education transformation, digital educational environment, spiritual and moral education, primary school student, digital technologies in education and upbringing.

\section{(C) 2020 Irina P. Ilinskaya}

This is an open access article distributed under the terms of the Creative Commons Attribution License (CC BY 4.0), which permits unrestricted use, distribution, and reproduction in any medium, provided the original author and source are credited.

Published by Kazan federal university and peer-reviewed under responsibility of IFTE-2020 (VI International Forum on Teacher Education) 


\section{Introduction}

One of the modern trends in the education's development worldwide is its digitalization. The society's development is closely attached to the new technologies' development, and the information technologies' (IT) introduction in the educational process has become an integral part of social development, one of the sides of this process. At the same time, active education's digitalization can have negative consequences. These include: a decrease in the level of students' physical and mental health (valeological aspect); rapid fatigue from the use of ICT tools (screen flickering, etc.); dependence on ICT when choosing information search methods; lack of direct contact between the teacher and the student ("live" communication between the teacher and the student) which can damage the spiritual and moral formation of the child's personality. Also, the disadvantages of the education's digitalization that negatively effect on the spiritual and moral sphere's development of the child's personality include an increase in the child's emotional discomfort, a lack of ability to resolve the simplest conflict, increasing irritability, aggression, consumption orientation, autism, hyperactivity, impatience, focus mainly on short-term goals. The digitalization's disadvantages in the fields of professional and general education are different. The school education's digitalization disadvantages also include a decrease in the level of student's social skills, total control over the child and his family, game addiction as a result of the digital educational environment's gamification and computer's and internet's availability, etc. (Molchanova, 2020).

However, digital technologies' possibilities, which help to increase students' level of intelligence, become obvious. Such children tend to focus on a high level of achievement, they value such qualities as honesty and frankness, but are they capable of such qualities in relation to others, to their parents? Because children tend to hide the content of their work with gadgets from parents, teachers, they are constantly busy, immersed in their own affairs and are not interested in the state of parent's health, adult's affairs, turning to them only when necessary for their part, which is also expressed the consumer attitude of the younger generation to life. Defined area of problems and features of education's digitalization allows us to determine the contradiction between its necessity and a decrease in the spiritual, moral and cultural potential of education.

\section{Purpose and objectives of the study}

The purpose of our research is to understand the trends in the development of education's digitalization and identify the pedagogical conditions of younger generation's spiritual and moral education in the era of educational system's digitalization. 


\section{Literature review}

As Strekalova notes, education digitalization is the next step after the educational environment's saturation with IT, which has already taken place, and it is under active development (2019). Problems of education's digitalization are actively discussed today by Russian scientists (Bondareva \& Petrova, 2019; Kozlova, 2019; Safuanov, Lekhmus, \& Kolganov, 2019; Avadaeva et al., 2018)

We are searching for a methodology and methods for organizing the digital educational environment (DEE). Avadaeva, Vezetiu and Orlova note that the modern educational environment is not sufficiently developed today, and demonstrates a noticeable lag from the modern digital economy's requirements. The authors note that the Russian school is overly committed to traditional technologies, and it needs yet a serious modernization, leading to radical changes in the entire education system (Avadaeva et al., 2018).

Such scientists as Safuanov, Lekhmus, Kolganov (2019), Petrova, Bondareva (2019), Kozlova (2019) and Poshekhonova (2018) are engaged in the search for ways to use digital technologies. Scientists agree that the use of digital technologies is a necessary condition for the development of pedagogy and education in modern conditions. The rapid development of digital technologies, which have huge potential, invariably leads to the education's transformation, and infinitely expands the educational space. Economy's digitalization, provision of digital resources and technologies for high-tech production, service and management bodies invariably entail the creation and development of the digital age's school.

However, digital technologies' possibilities, which help to increase students' level of intelligence, become obvious. The evidences of this fact is research results of such scientists as Petrova, Bondareva (2019) and Kozlova (2019). Today, there is an increase in the category of gifted children, "the phenomenon of child multitasking" is developing (the ability to perform several operations, functions, affairs at the same time), which is recognized by many scientists and teachers as positive effect of education's digitalization, but, at the same time, it has its negative features. This is the loss (or deficiency) of children's ability to concentrate, and stressors in this type of activity, and so-called "noise-dependence" of the work style, when the simultaneous performance of many tasks does not allow to perform any of them qualitatively, and, as a rule, they are performed with errors. A modern primary school student, a younger teenager, a child of the digital age, «Digital Native» (Prensky, 2020) owns digital technologies, he is able to create presentations, websites, flash movies, and develop his creativity through these technologies.

A necessary condition for education's digitalization is the training of literate and competent teacher who knows modern digital practices and models for organizing the educational process (Kozlova, 2019; Mitrofanov, 2007). 
At the same time, a number of authors dealing with the problems of younger generation's spiritual and moral education and the search for effective ways to introduce students to humanistic values, note the disadvantages of education's digitalization and the negative impact of this process on the formation and development of personality in childhood (Podstrakhova, 2019; Molchanova, 2020; Faktor, Kamolov, \& Nikandrova, 2018).

The absence or lack of tools for diagnosing and evaluating the digital educational environment, which acts as an objective reality, is also alarming. The rapid development of digital technologies, changes in the DEE, as well as their novelty do not allow us to conduct a traditional survey and obtain objective results of digital technologies' impact on the development of a child's personality.

However, scientists attempt to describe possible risks of introduction and development of digital technologies and resources, to predict the results of determining strategies for the development of digital society as a whole (Faktor, Kamolov, \& Nikandrova, 2018).

\section{Methodology}

Digitalization is a new approach to organization and development of a person's life and professional space, a new social situation of development. Digitalization in education is a new paradigm, which provides new opportunities and forms of educational subject's communication and interaction; an effective means of getting quality education. Digital technologies allow you to build individual educational routes, make the educational environment unified, unlimited, accessible, allowing education in several directions at once, combine study and work and other activities and receive information in accessible, fun, playful game.

Despite positive trends in the development of education's digitalization, the problems of the digital educational environment's organization and functioning are clearly identified. Thus, the education's digitalization in practice does not always lead to high-quality education for subjects. For example, the use of play-based methods DEE in primary school, will certainly stimulate the cognitive activity of primary school students, but distance learning, which widely implemented today at the higher school level often convince teachers of students' negligent attitude to obtaining professional knowledge, both in Russia and abroad.

In the process of education's digitalization and transformation, such tasks as the person's intellectual development, communication culture's development, the development of critical thinking and creative abilities of the individual come to the fore. However, in our opinion, such a necessary and significant 
component, such an education's important task as the spiritual and moral formation of the person is significantly lost.

At the same time, digital technologies are based on the use of ICT, Internet and software and are recognized as an effective education's means. These include cloud technologies, e-learning technology, online learning, gamification technology, etc. (Avadaeva, et al., 2018).

However, many of these technologies have their drawbacks. The most frequently mentioned is the absence or significant reduction of face-to-face communication between the teacher and students, between students and their parents. For the professional education system, this threatens with the loss of value guidelines and meanings, for primary school students, the threat lies in the inhibition of the speech development, the development of dyslexia and dysgraphia and the subsequent deficiencies in the development of thinking and the personality as whole. Of course, this is not the entire spectrum of the listed negative consequences of reducing the direct communication between the student and the mentor, but the most striking and the general one. No less often, in our opinion, gamification is mentioned, which on the one hand motivates and stimulates the process of learning (and independent learning), the process of developing creativity in the individual, and on the other hand - develops game addiction, leads to "digital dementia", reduced social skills, increased nervousness, and does not protect against "unverified" information on the Internet. So, for example, viewing a web page aimed at creating a value attitude to your family (which, of course, helps the teacher to solve the problems of spiritual, moral and patriotic education of younger students, the problems of interaction between school and family) leads us to one of the resources for designing postcards, where we see pictures and inscriptions that are not children's content, but dirty, vulgar, and unacceptable for use in the school educational environment. At the same time, on the forum, the colleagues of the teacherdeveloper approve and thank him for creating this web quest, which indicates teamwork in its use. This is evidenced by the protocol, which reflects the registration and teachers' consent to be responsible for the information offered to students from the World Wide Web.

The modern education system provides the spiritual and moral development of the younger generation, this is one of its main tasks. And if the student's image as the end result of the education process today should change in accordance with the development strategy of "Smart Home" - "Smart City" - "Smart Planet", in accordance with the requirement for artificial intelligence to appear on the labor market to perform routine processes, then, in our opinion, for this, a predictive model of the effectiveness DEE to be developed, regarding on its impact on the health and development of younger generation, the impact on the cultural and spiritual sphere of the person. A model, that would allow you to define as - negative or positive - and how much the above positive and negative trends in the education's digitalization development affect the 
system of cultural, spiritual and moral values of children and youth, in particular the development of their independence, creativity, communication skills, collective activities, processes of self-regulation, moral qualities (diligence, responsibility, honesty, modesty, charity, compassion, mercy, and etc.), a system of physical and mental health of the individual.

The transition from an industrial society to an information society, and as the result to an information educational paradigm, entails a change in the way of life and person's value system. As Mitrofanov notes, "the role of cultural leisure in relation to material values" increases (Mitrofanov, 2007). The author writes that a society aimed at goods' production and consumption becomes a society aimed at the production and consumption of intelligence and knowledge. At the same time, the person's spiritual and moral sphere impoverishment can lead to the sad consequences of the transition from the formation of false needs to false ideals (Anokhin \& Ilinskaya, 2015). This leads us to the logical question of how important are the cultural and axiological education's aspects for us, how important are the values of spiritual and moral culture for a modern person? These values are called traditional. These include health, family, religion, upbringing, love, friendship, freedom, education, work and etc. The system of such values may well fit into the circle of Orthodox values, values of Russian world (Ilinskaya, 2014). The same values are presented in the legislative and regulatory documents, regulating relations in the field of the national educational system. Thus, in the Concept of spiritual and moral development and education of Russian citizen's personality, Danilyuk, Kondakov and Tishkov (2009), the Federal state educational standard of primary general education (GEF) (2018) defines the national educational ideal, orientation to the system of basic values, “students' spiritual and moral development and education, providing for their adoption of moral norms, moral attitudes, national values" (2018, p. 10) among which are patriotism, citizenship, family (love and loyalty, health, respect for parents, care for older and younger, for procreation), work and creativity, science, traditional Russian religions, art and literature, etc. (Danilyuk, Kondakov, \& Tishkov, 2009).

Since the education's transformation was identified as a consequence of changes in the social development of society. We are talking about the change in the value system in modern society, about the values' transformation during the transition from generation X (1963-1982) to generation Y (1983-2002) and generation Z (2002-2003). Russian scientists Bogdanov (2018), Voskresensky (2018), Kamolov (2018), Podstrakhova (2019), Starczev (2018) note, that in the digital age, the main values, that serve as life guidelines and are the basis for youth behavior are high self-esteem (egotism,egocentrism), personal opinion, self-confidence (often unconfirmed and unjustified), mobility, speed, flexibility, ease of perception of a new, frequent change of place and environment, orientation to the rapid rise in the social elevator, comfort, multidirectional life and professional interests, orientation to the present and fast-reaching goals, hedonism (pleasure orientation), weak (or lack of) concern for the future (Bogdanov, Sultanov, \& 
Voskresenskij, 2018; Podstrakhova, 2019; Faktor, Kamolov, \& Nikandrova, 2018; Starczev, Grishanin, \& Kirillina, 2018). Some of the authors see positive aspects of the distinguished values and value orientations, believing that the traditional system of values is not necessary and "does not work" in society and the education system (generation $\mathrm{Z}$ is today's students, children and youth). Thus, Petrova and Bondareva point that "digital technologies, social networks and messengers have changed public values and led to the network identification of a person. A new type of students has begun, who independently determine their educational trajectory. They are motivated by personal development and self-determination, combining work with study" (Petrova, \& Bondareva, 2019). Others come to the disappointing conclusions about the failure of modern youth, and the need to build a human society based on a system of human relationship, rather than digital values.

Thus, it seems necessary to focus on the formulation of primary school students' spiritual and moral education problems in the digital age:

- will it be right to talk today about the problems of introducing primary school students to the spiritual and moral values of their ancestors, historical roots, the values of the Orthodox culture and the Russian world (orthodox values) or should they be recognized as inappropriate to the time and raise the question of changing the value system according to time and development society and technology (relative to generations)?

- How will we position the education's digitalization as a means of increasing its effectiveness, quality, or as the ultimate goal of the society's development and human development, realized through education?

Today, in Russian schools, the problems of children's spiritual and moral education are resolved on the basis of the Concept and the primary general education GEF (Danilyuk, Kondakov, \& Tishkov, 2009), therefore, on the basis of traditional spiritual and moral values. We see the need for conscious and purposeful actions to form the child's personality, rather than indulging the negative influences of the environment. So, for example, if a child's high self-esteem is not justified, then the adult's task, the task of the family and school, is to form an adequate self-esteem in him, and not accept the existing realities, as something inevitable and inappropriate change. If a child develops a tendency to expect undeserved benefits, social take - off, etc., then the task of home and school teachers is to teach him to work hard and form an understanding that "A cat in gloves catches no mice", "All in good time", "Diligence is the mother of success". Therefore, we think it is particularly important that adults understand the need to preserve the experience of previous generations, the cultural heritage of their people, and their identity, first of all, in 
national, professional, and social terms, and only after it - in digital terms (Ilinskaya, 2014; Smolonskij, 2014).

We often strive to develop the child in the current conditions, accepting without resistance the negative influences of the environment, accepting negative consequences as a given, as a consequence of environment's development, new values as something unchangeable, already happened and not subject to further change. However, the personality's development in the environment is a process of the mutual influence of the environment and the individual, while qualitative changes occur both in the individual and in the environment. Perhaps one of the reasons for this assessment of the education's digitalization and modern trends in the development of this process lies in the low level of primary school teachers' information literacy. The digital technologies' introduction requires overcoming the "digital divide" that has formed due to the lack of professors' and school teachers' competence. Often in the regions, we have a very uneven intermittent structure of general and professional education's digitalization: we implement breakthrough projects, build innovative digital schools and do not have time to prepare future teachers for the digital educational environment's implementation (DEE), develop its quality content and methodological support. The solution to these problems lies in the rational use of the DEE as a means, rather than developing it as an end in itself.

Thus, in the Belgorod region today, a new educational strategy is being successfully developed, aimed at forming the younger generation not as consumers, but as creators, a generation that is healthy in physical and spiritual and moral aspects. Schools with a digital educational environment already exist and are being built in the region. The first of them was the experimental school "Algorithm of success", a school with mobile e-education: instead of paper books, children are engaged in digital textbooks. Kids use e-books, students from grade 5 are given tablets, and high school students - laptops. All of them are connected to the "Lecta" digital educational platform. Just recently, another 1000 - seat school that meets all modern requirements was opened - "Vector of success". At the same time, these and other schools in the region implement the "Friendly school" strategy, based on the need to foster kindness, good feelings, goodwill, and the development of students' emotional culture. The implementation of the strategy should influence the formation of tastes, interests, independence, and the formation of a value system for schoolchildren. This should become not just a style of communication, but an unwritten rule and norm of behavior and attitude. A significant component of the strategy is the inclusion of students in activities (project, municipal, socially significant, public, collective), which contributes to the education of students ' hard work. Of course, this increases the requirements primarily for the teacher, his personal and professional qualities, but also forces students and parents to respect the status of the teacher, his honor and professional dignity. 
Thus, in our opinion, a reasonable balance can be achieved between traditional and e-learning in schools, and then in universities, and will allow achieving the highest results in the spiritual and moral development of the younger generation.

\section{Results}

Creating a digital educational environment in a school - is a significant modern assistance to the teacher, and not the end in itself of educational system, which strives for technological rather than humanistic values. In the educational environment, you can always identify the factors that contribute to the formation of primary student's spiritual and moral culture, which will help to determine the most effective pedagogical conditions for this process.

The search for ways of younger generation's spiritual and moral education is impossible without understanding the importance of not only external, but also internal conditions for the child's development, activation of child's internal capabilities and potentials, the individual's desire for independent development, spiritual growth, and self-improvement.

The pedagogical conditions of primary school student's spiritual and moral education in digital educational environment are:

- building a digital educational environment based on traditional humanistic values;

- providing the child with the opportunity to form positive moral qualities of the person;

- involving students in the study of their people's cultural heritage;

- building the educational process on the basis of basic national values;

- reliance on the education's content aimed at spiritual and moral education of the individual;

- the optimal combination of various forms, means, methods, technologies of individual's spiritual and moral education;

- training of teachers who know how to build a digital educational environment and are able to reproduce and broadcast spiritual and moral values. 


\section{Discussions}

The analysis of literary sources, identification and understanding of positive and negative trends in the modern domestic education's development and the organization of the school digital educational environment allowed us to identify the contradiction and search for ways to resolve it.

We identify pedagogical conditions for primary school students' spiritual and moral education in the digital educational environment, aimed at learning and understanding traditional values using digital technologies.

\section{Conclusion}

In the pursuit of digital technologies, their implementation and development as a means of obtaining quality education, the main goal and essence is slipping away - personality development, its spiritual and moral potential. A person is becoming a part of the digital environment, an element embedded in it and our task today is to carefully ensure that he does not lose his human and personal identity in favor of a digital identity, so that the boundaries between a living human face and a face of petrified, emotionless digital being are not erased. So that we do not forget that education's digitalization is a means to an end, it is not the end itself. The purpose of education is to educate a living person with a high level of personality's spiritual and moral culture and intelligence.

It is important that a person owns the technology and not the technology owns a person. It is easier to manage a digital society, but is it easier for person to live and develop in such society? Will a person lose his "independence", his individuality, his human essence?

Creating conditions for primary school students' spiritual and moral education in the digital educational environment is a new direction that requires further study and research of the above-mentioned problem.

\section{Acknowledgements}

The work is performed on the basis of the Belgorod state national research University.

\section{References}

Avadaeva, I. V. Anisimova-Tkalich, S. K., Vezetiu, E. V., Vovk, E. V., Goldenova, V. S., Grebennikova, V. M., ... Sher, M. L. (2018). Methodological foundations of modern digital educational environment's formation. Retrieved from http://scipro.ru/conf/monographeeducation-1.pdf 
Anokhin, D. G., \& Ilinskaya, I. P. (2015). Polycultural education of primary school students by means of folk art. Bulletin of the Kostroma state University named after N. A. Nekrasov. Pedagogy. Psychology. Social work. Juvenology. Sociokinetics, 2, 149-153.

Bogdanov, S. I., Sultanov, K. V., \& Voskresenskij, A. A. (2018). Post-material values and life orientations of the generation: digital youth in the educational system of modern Russia. Izvestiya RSPU named after A. I. Herzen, 187, 24-30.

Danilyuk, A. Ya., Kondakov, A. M., \& Tishkov, V. A. (2009). The concept of spiritual and moral development and education of Russian individual citizen in the field of General education. Moscow: Prosveshchenie.

Faktor A. M., Kamolov, S. G., \& Nikandrova, A. A. (2018). Human values in the digital age. Russia, modeling, optimization, and information technology. Scientific journal, 2(21), 86-103.

Federal State Educational Standard for Primary General Education (2018). Retrieved from https://fgos.ru/

Ilinskaya, I. P. (2014). Spiritual and moral education of primary school children by means of artistic culture of different nations. Nachalnaya shkola, 6, 16-21.

Ilinskaya, I. P. (2014). Spiritual and moral education of primary school students in a multi-ethnic educational environment. Yaroslavl pedagogical Bulletin, 1(2), 209-215.

Kozlova, N. Sh. (2019). Digital technologies in education. Bulletin of the Maykop state technical University, 1(40), 85-93.

Mitrofanov, E. P. (2007). The process of society's informatization. Bulletin of the Chuvash University, 4, $395-402$.

Molchanova, E. V. (2020). About the pros and cons of modern education's digitalization. Problems of modern pedagogical education, 133-135. Retrieved from https://cyberleninka.ru/article/n/o-plyusahi-minusah-tsifrovizatsii-sovremennogo-obrazovaniya/viewer

Petrova, N. P., \& Bondareva, G. A. (2019). Digitalization and digital technologies in education. The world of science, culture, and education, 5(78), 353-355.

Podstrakhova, A. V. (2019). Generation of the "digital age": life orientations and educational values. Young scientist, 15(253), 287-290. 
Poshekhonova, V. A. (2018). Educational humanitarian technology of the digital generation. Pedagogical education in Russia, 5, 13-20.

Prensky, M. H. (2020). Sapiens Digital: From Digital Immigrants and Digital Natives to Digital Wisdom. On the Horizon, 9(5). Retrieved from https://www.wisdompage.com/Prensky01.html

Strekalova, N. B. (2019). Risks of implementing digital technologies in education. Bulletin of Samara University. History, pedagogy, philology, 25(2), 84-88.

Safuanov, R. M., Lekhmus, M. Yu., \& Kolganov, E. A. (2019). Digitalization of the education system. Bulletin of the Ufa state petroleum technological University, science, education, and economics. Series economy, 2(28), 108-113.

Smolonskij, S. I. (2014). Pedagogical conditions of primary school students' spiritual and moral education. Bulletin of the Kostroma state University named after N. A. Nekrasov, series Pedagogy, Psychology, Sociogenetics, 2(20), 117-119.

Starczev, A. A., Grishanin N. V., \& Kirillina N. V. (2018). Identity and identification in social networks. Communicology, 6, 76-87. 